\title{
Developing a Method for Comparing the Elite Sport Systems and Policies of Nations: A Mixed Research Methods Approach
}

\author{
Veerle De Bosscher \\ Vrije Universiteit Brussel \\ Simon Shibli \\ Sheffield Hallam University \\ Maarten van Bottenburg \\ Utrecht University
}

\section{Paul De Knop and Jasper Truyens \\ Vrije Universiteit Brussel}

\begin{abstract}
This article aims to make a contribution to comparative sport research and details a method for comparing nations' elite sport systems less descriptively by measuring and comparing determinants of national competitiveness quantitatively. A mixed methods exploratory sequential design is used, consisting of two distinct phases. After qualitative exploration, a conceptual model was developed, revealing that there are nine sport policy dimensions or 'pillars' that are important for international sporting success. This article focuses on a second quantitative phase, where the model was tested in a pilot study with six sample nations to develop a scoring system. Data from each nation were collected through an overall sport policy questionnaire completed in each country, and through a survey with the main stakeholders in elite sport, namely athletes $(n=1090)$, coaches $(n=253)$, and performance directors $(n$ $=71$ ). Reflecting recognized principles of economic competitiveness measurement, this article demonstrates how 103 critical success factors containing quantitative and qualitative data can be aggregated into a final percentage score for the sample nations on each pillar. The findings suggest that the method is a useful way for objective comparison of nations, but it should not be isolated from qualitative descriptions and from a broader understanding of elite sport systems.
\end{abstract}

\footnotetext{
De Bosscher, De Knop, and Truyens are with the Dept. of Sport Policy and Management, Vrije Universiteit Brussel, Brussels, Belgium. Shibli is with Sheffield Hallam University, Sheffield, UK. Van Bottenburg is with Utrecht University, Utrecht, the Netherlands.
} 
Competition in international sport is increasing and more nations are adopting strategic approaches to develop world class athletes. Over time, this phenomenon has resulted in increasing amounts of money being invested in elite sport development by many nations (De Bosscher, Bingham, Shibli, van Bottenburg, \& De Knop, 2008). What has emerged is an interest in sport systems and a desire by researchers and policy makers to explain sport success, mainly with reference to the Olympic Games. In this regard, an emerging body of literature developed at the end of the 20th century around the sport systems and policies of different nations (e.g., Broom, 1986, 1991; Buggel, 1986; Chalip, 1995; Digel \& Barra, 2004; Digel, Burk, \& Sloboda, 2003; Digel \& Fahrner, 2003 ; Douyin, 1988; Krüger, 1984; Riordan, 1989, 1991; Sedlacek, Matousek, Holcek, \& Moravec, 1994; Semotiuk, 1990). These studies have primarily focused on a description of the organizational context of elite sport and the sport policies in different nations. Analysis of this literature concludes that relatively few comparative studies have been conducted in sport (Henry, Amara, \& Al-Tauqi, 2005; Henry, 2007; Houlihan, 1997; Bergsgard, Houlihan, Mangset, Nødland, \& Rommetveldt, 2007) and some comparative descriptive research on elite sport policy development has only emerged over the past few years (e.g., Bergsgard et al., 2007; Digel, Burk, \& Fahrner, 2006; M. Green, 2005; Green \& Collins, 2008; Green \& Houlihan, 2005; Houlihan \& Green, 2008). This deficiency in the literature is caused by the difficulty of comparing nations and sport systems on a directly comparable basis, due to cultural differences and the uniqueness of each sport system. Furthermore, Henry et al. (2005) noted that there appears to be a lack of standardization in the research methods used to make comparisons, as well as limited publicly available and quantifiable data on sport policies. These constraints are indicative of the complexity of cross-national comparisons.

With this context in mind, we seek to address a methodological issue in sport management literature via this paper. The aim is to explore a method for comparing nations' elite sport systems less descriptively by measuring and comparing the critical success factors of elite sport systems - or the determinants of national competitiveness (Depperu \& Cerratu, 2008; Porter, 1990)—quantitatively. According to Garelli (2008), "The measurement of world competitiveness is routinely used in economic studies to provide a framework to assess how nations manage their economic future" (p. 1). In this article, we attempt to replicate the approach in an elite sport setting and in this respect explore a method to assess how nations might manage their future success in international sport competitions. By considering how competitiveness is measured in the economic sector, we provide an initial exploration of the development of a measurement tool that can be used to compare elite sport systems. Hence, we endeavor to simulate debate in the field of international comparative sport research. In this respect our study differs from previous elite sport research because of the use of quantitative data and the introduction of 'measurement' in an area (comparing elite sport policies and systems) that is essentially qualitative in nature.

The methods explored in this paper are part of a large scale project, called the SPLISS study, which aimed to improve the development of theory concerned with "Sports Policy factors Leading to International Sporting Success" (De Bosscher, De Knop, \& Van Bottenburg 2007; De Bosscher et al., 2008). The SPLISS study employed mixed research methods with a three phase (sequential) exploratory design: a qualitative phase followed by two quantitative phases (see Figure 1). "This 


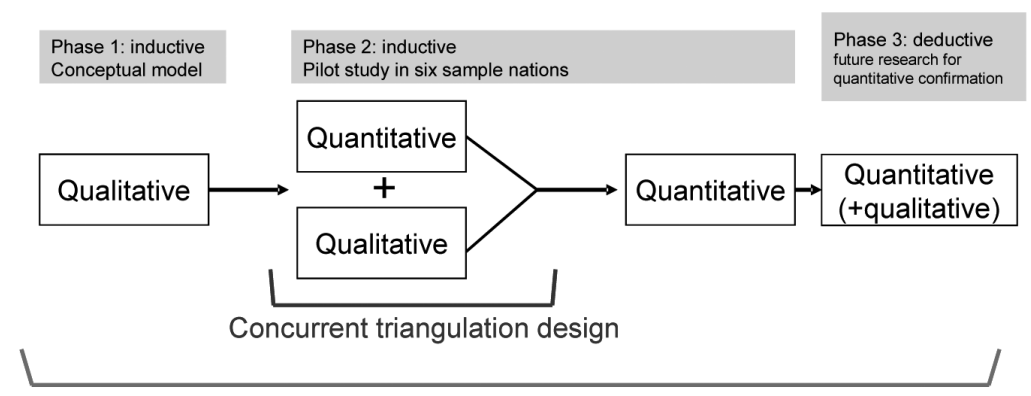

Sequential exploratory design

Figure 1 - Summary of the mixed research methods design used to measure competitiveness of nations on elite sport.

design is based on the premise that an initial qualitative exploration is needed for one of several reasons: measures or instruments are not available, the variables are unknown, or there is no guiding framework or theory" (Creswell \& Plano Clark, 2007, p. 75). In this respect, the first phase of the SPLISS study was concerned with the development of a conceptual model, which is described in detail in previous research (De Bosscher, De Knop, van Bottenburg, \& Shibli, 2006).

This article is primarily concerned with the second phase of the research, that is, to explore a method to measure quantitatively the determinants of competitiveness of nations at an elite sport policy level. During this stage, triangulation of methods was used to set up an international comparative pilot study in six sample nations. Mirroring economic competitiveness studies, we outlined a method in this article by which the nine pillars and its critical success factors (CSFs) are operationalized through qualitative and quantitative data that are subsequently transformed into a scoring system.

The third phase of the design in Figure 1 concerns issues for further research to confirm the method to measure the competitiveness of nations deductively; as well as exploring the relationships between sport policies and international sport success.

\section{Cross-National Comparative Studies}

There are a number of international studies in sport that analyze and compare one specific topic by examining general trends, for instance in youth sport, sport for all, or national sport policies (e.g., Kamphorst \& Roberts, 1996; De Knop, Engström, Skirstad, \& Weiss, 1996; Chalip, Johnson, \& Stachura, 1996; Dacosta \& Miragaya, 2002; Van Bottenburg, Rijnen, \& Van Sterkenburg, 2005). These descriptive studies illustrate the difficulties of operationalizing concepts in simple, quantifiable, comparable units. To address this issue, another study-the COMPASS project (Gratton, 1999) - sought to influence the methods of data collection in national sport participation surveys to identify statistical patterns. Such studies, although useful, often lack explanations as to why the observed associations such as sport participation occur (Henry et al., 2007). 
In the case of elite sport development, comparative literature has grown rapidly since 2000, mainly because of the desire by policy makers and researchers to explain why some nations are more successful in international sport competitions than others. For example Digel and Barra (2004), Digel, Burk and Sloboda (2003, 2006), Digel and Fahrner (2003), Digel, Fahrner, and Utz (2005), Digel and Kruse (2004), Digel, Miao and Utz (2003) attempted to make an international comparison of elite sport in the seven nations that were included in their large scale study. They produced a vast amount of information on each nation and summarized the common structural features and differences (Digel, Burk, \& Fahrner, 2006). Furthermore, the recent study by Green and Houlihan (2005), are rare examples of comparing elite sport systems using a framework (the advocacy coalition framework), to compare three nations at both overall and sport specific levels. Subsequently, Houlihan and Green (2008) described systems, structures, and public policy in nine nations, as a development of the conclusions in their earlier work (2005). In another study, Bergsgard et al. (2007) compared four nations focusing mainly on the factors that shape sport policy. Interestingly, they used their comparative data to develop theoretical explanations of policy change and regimen type. All of these studies sought to find similarities and trends in the elite sport systems of different nations and different sports and they are characterized by being descriptive comparisons. Oakley and Green (2001) developed the research agenda by indicating that there was also a general need to investigate differences between nations.

Useful methodological insights can be observed when considering research beyond the sport sector, for example in the economic or political sectors. One notable work is by Esping-Andersen (1990) who developed dimensions of comparative welfare states and demonstrated the clustering of 18 advanced capitalist democracies into three distinct regimes (conservative, liberal, and social democratic). Although the categorization of welfare regimes has been criticized on a number of grounds (Bryson, 1992; Castles \& Mitchell, 1992; Shainsbury, 1994), this work was pioneering in comparative research for identifying one of the most sophisticated sets of characteristics concerning welfare states, and for translating generally qualitative indicators into more quantitative indicators. With regard to the competitiveness of nations, Porter (1990) identified and aggregated the characteristics of national competitive advantage into a systemic model, called the "competitiveness diamond," consisting of four determinants that are compared in the ten most competitive nations. Porter (1990) stated that it is far more difficult to compare nations than firms, because firms compete but governments, to a large extent, influence the preconditions of these firms. Very few studies have considered the issue of multicountry competitiveness (Önsel, Ülengin, Ulusoy, Aktas, Kabak, \& Topcu, 2008). Leading publications for the evaluation of competitiveness measurements of nations are the International Institute for Management Development (IMD) World Competitiveness Yearbook or the Global Competitiveness Report from the World Economic Forum (Önsel et al., 2008).

\section{The Complexity of Cross National Research}

Although past studies often questioned whether nations are suitable units for comparison, international comparative research between nations is the only means by which one can detect the variables which explain international sport success and 
the strategies nations use to develop such success. This is because elite sport is international by definition (van Bottenburg, 2000). A number of researchers agreed that there are no universal or perfect methods in cross national (sport) studies (DaCosta \& Miragaya, 2002; Hanafy \& Krotee, 1986; Haag, 1994). Cross national sport studies are often considered to be problematic because sport is embedded in a broader cultural context, where beliefs, norms, and values, for example those associated with social class, gender, disability, and ethnicity, have been shown to have had a marked impact on the character of sport policy (Houlihan \& Green, 2008). Consequently, policy instruments are often dependent on politics and policy regimes, which implies that similar policy actions may have different outcomes in different nations. Houlihan and Green (2008) argued that some policy sectors, such as sport, may be less deeply rooted in the culture of a political system than other core welfare services such as those on which Esping-Andersen (1990) focused.

The boundaries of international comparative studies are often underestimated. Henry et al. (2005) identified four types of comparative analysis on sport policies, each accompanied with their specific weaknesses and core problems. The types of comparative analysis reveal difficulties related to operationalization, comparability, measurement, explanations of causality, validation, reliability, interpretation, moving beyond the descriptive, and balancing between global and local factors. The main point of note in cross-national comparative studies is to identify how these typical problems can be reduced. Hofstede (1998) provided the simile that every comparison of values and norms between nations is like a comparison between apples and oranges. It is important to find a common language for those factors that can be compared:

Popular wisdom deems that one cannot compare apples with oranges. But what do we mean by 'compare'? Scientifically speaking, apples and oranges come under the general category of 'fruits' and can be compared on many criteria, such as availability, price, color, vitamin content or keeping quality. Comparing apples with oranges, cross-cultural psychologist Harry Triandis once said, is okay as long as we possess a fruitology, a theory of fruits. (1998, p. 16)

Therefore our first challenge was to identify this 'fruitology' and the policy indicators that can be used to make appropriate comparisons. This fruitology is created in a theoretical model that has been used in this paper as discussed in the next section.

\section{Method}

The next section endeavors to provide a framework for assessing how nations manage their success in international sport competitions, by examining how competitiveness is measured in economic literature. Although a sport policy setting differs from an economic setting, notably because its goals are not financially focused, the methods used in economics may be a source of inspiration for making similar analyses in sport. Meanwhile, due to the specificity and complexity of sport, the methods used in this article may open a dialogue with other researchers in sport working in similar areas. The basic principles of economic competitiveness studies are quite similar in design. Linssen (1998) used the following four steps, to measure 110 indicators clustered in ten determinants and compared across six nations: 
(1) generating the determinants of competitiveness; (2) expressing relevant factors in indicators and sub indicators; (3) scoring each indicator and in some cases applying weightings; and (4) comparing the scores and, if possible, explaining differences between nations. Similar methods can be found in the IMD World Competitiveness Yearbook or the Global Competitiveness Report (World Economic Forum, 2008). For example in the World Competitiveness Yearbook, 55 economies are analyzed and ranked on 331 criteria that are grouped into 20 factors and then regrouped into four competitiveness determinants (Rosselet, 2008). Reflecting these studies, our article details how a scoring system was developed in elite sport through a pilot study with six nations.

A mixed methods exploratory sequential design was used, consisting of two distinct phases: a (mainly) qualitative phase followed by a (mainly) quantitative phase (Creswell \& Plano Clark, 2007). The first phase, the development of a conceptual framework of sport policy factors leading to international success, builds on our earlier work and will be discussed in the next section. The second stage consisted of obtaining complementary qualitative and quantitative data to implement the conceptual framework in a pilot study with the six sample nations. The qualitative and quantitative data are subsequently transformed into a quantitative scoring system to measure the competitive position of nations and thus facilitate the comparison of elite sport policies to be made less descriptively. This intermediate step was needed to increase the criterion validity (development of a tool that may increase insights into a possible relationship between sport policies and success) and construct validity (by refining the explorative framework and its items). The focus of our article is related to this second stage, which was a precondition for a third phase, planned in future research: a deductive method to validate the theory; using factor or cluster analysis to validate the subscales; reliability analysis to assess the internal consistency; and correlations to discover possible causes and effects. The appendices (A1, B1, C1) provide detailed guides for readers who wish to see, in greater depth, the different research steps taken in this study.

\section{Instruments}

Phase I: A Conceptual Model of Sport Policy Factors Leading to International Sporting Success (SPLISS Framework). Measurement implies a theory about the operations of, or the relationships among, a set of variables relevant to the phenomenon being investigated (Pedhazur, \& Schmelkin, 1991). In this respect, the lack of an appropriate method to compare elite sport policies also originates from the lack of a theoretical model of sport policy factors leading to international sporting success, or a competitiveness framework that shows how nations manage their success in international sport competitions (De Bosscher et al., 2007). When considering economies as a whole Porter (1990) stated that "competitiveness" of nations is usually ill defined and he proceeds to point out that "instead of seeking to explain 'competitiveness' at the national level, we must first understand the determinants of productivity" (1990, p. 9). A qualitative exploration of sport policy factors that influence international success-or the determinants of productivity in elite sport- therefore formed the first part of the study. We used a nine pillar model derived from previous research as a basic analytical framework for international comparison (De Bosscher et al., 2006). This model was developed because of 
an identified gap in the literature and the lack of an empirically grounded theory on the factors, which determine international sport success. A detailed diagram of the procedures used in this first stage of this study is included in appendix (A1).

Content analysis was used to consolidate all relevant sources from a comprehensive body of literature on the former Soviet Union and East Germany (e.g., Broom, 1991; Douyin, 1988; Krüger, 1984; Riordan, 1989; Semotiuk, 1990) and more recently on the organizational context of countries in elite sport (e.g., Clumpner, 1994; Digel et al., 2006; Green \& Houlihan, 2005; Larose \& Haggerty, 1996; Oakley \& Green, 2001; Stamm \& Lamprecht, 2000). This literature was supplemented by studies at the microlevel, which attempted to understand the determinants of success for individual athletes rather than nations (e.g., Conzelmann \& Nagel, 2003; Duffy, Lyons, Moran, Warrington, \& Macmanus., 2001; Gibbons, McConnel, Forster, Riewald, \& Peterson, 2003; Greenleaf, Gould, \& Diefen, 2001; Nys, 2002; Unierzyski, 2002; Van Bottenburg, 2000). Two independent researchers employed inductive procedures to cluster relevant raw data from this extensive body of literature into first order and second order themes until interpretable and meaningful key categories were found (Gliner \& Morgan, 2000).

In addition to this literature review, and to increase the face and content validity of the theory development, two explorative studies were also conducted (De Bosscher et al., 2007):

(1) one with international tennis coaches from 22 nations to approach key success drivers from an expert perspective in a specific sport; and

(2) one with 114 Flemish (i.e., the northern, Dutch speaking part of Belgium) elite athletes, 99 coaches, and 26 performance directors to approach key success drivers from a consumer perspective.

Both surveys used simple open-ended questions to identify the external factors that make the most significant contribution to the international sport success of athletes. Similar inductive procedures to those described above were used to analyze the data.

Subsequently, to increase validity and interpretive consistency (Tashakkori \& Teddlie, 2003), the list of different items and (sub) themes, both from literature and preliminary research, was presented to an international consortium group of seven researchers from the United Kingdom, the Netherlands and Belgium (further details are provided in the section entitled 'organization of the research') with expertise in elite sport policy research, who were independently asked to cluster the items into categories. This categorization was compared and discussed during a two day meeting. Where different interpretations emerged, the items were regrouped and discussed until consensus was achieved. Three additional dimensions were identified in the preliminary explorative surveys namely: (1) media-attention; (2) specific sport culture, and (3) athletes' personal environments (e.g., parental support). While all three factors are arguably highly influential, they cannot be directly affected by sport policies and were therefore excluded from the study.

The list of agreed items was grouped thematically according to the different stages of athletic development as identified by Wylleman, De Knop, and Sillen (1998). Finally, based on both the literature overview, and success factors according to a "consumer" and "expert" perspective, it was concluded that the key success 
drivers, which can be influenced by policies, can be distilled down into nine key areas or "pillars" (see Figure 2).

These pillars are situated at two levels:

- Inputs are reflected in Pillar 1, as the financial support for sport and elite sport. Countries that invest more in (elite) sport can create more opportunities for athletes to train under ideal circumstances.

- Throughputs are the processes ("what" is invested and "how" it is used) in elite sport policies, which may lead to increasing success in international sport competitions. They refer to the efficiency of sport policies, that is, the optimum way the inputs can be managed to produce the required outputs. All of the Pillars 2-9 are indicators of the throughput stage.

Inputs and throughputs in this model are the sport policy factors that may increase chances of international success (or, outputs), but do not guarantee success. Outputs are indicators of the success of nations in elite sport competitions that result from a combination of these factors (i.e., the meso-level) and many extraneous factors, situated at the macro-level (e.g., population, wealth, natural resources, cultural factors, religion) and microlevel (e.g., the individual athlete and their close environment), which cannot be influenced by sport policies (De Bosscher et al., 2006). These factors are therefore excluded from this study. There are various methods by which the outputs of an elite athlete production system can be measured, such as: the number of medals won during the Olympic Games or other events: top six or eight places; the relative success (e.g., controlling for population, wealth) or even the number of participants qualifying to take part. All of these methods appear to correlate significantly $\left(r_{s}>0.8\right.$; De Bosscher et al., 2007). Differences emerge when a different portfolio of sports is used (e.g., summer or winter sports), or absolute versus relative success is measured by controlling for macro-level factors.

The pillars presented in the SPLISS model in Figure 2 are nine general elite sport policy dimensions under which all the factors influenced by sport policies, can be classified. These pillars were specified by a set of critical success factors (CSFs), of which 103 have been operationalized in the subsequent pilot study. We refer to our earlier work for a fuller explanation of this model (De Bosscher et al., 2006; De Bosscher et al., 2007; De Bosscher, De Knop, van Bottenburg, Shibli, \& Bingham, 2009).

This SPLISS model provides only a tentative theoretical assumption on sport policy factors that lead to international success. This research indicated that "its function is not deterministic, rather it aims to identify pivotal issues and to generate crucial questions in a benchmark study of elite sport systems" (De Bosscher et al., 2006, p. 209). Based on a comprehensive body of literature and the opinions of both stakeholders and experts, albeit in a limited context of countries, we consider the model to be reasonably face and content valid. Nonetheless, "it is impossible to conduct a model that is totally construct valid because of the many extraneous factors that influence success and because it is impossible to create one single model for explaining international success" (De Bosscher et al., 2006, p. 209). Application of the model in an empirical environment is required to understand how the pillars are activated in different nations and how the different critical 


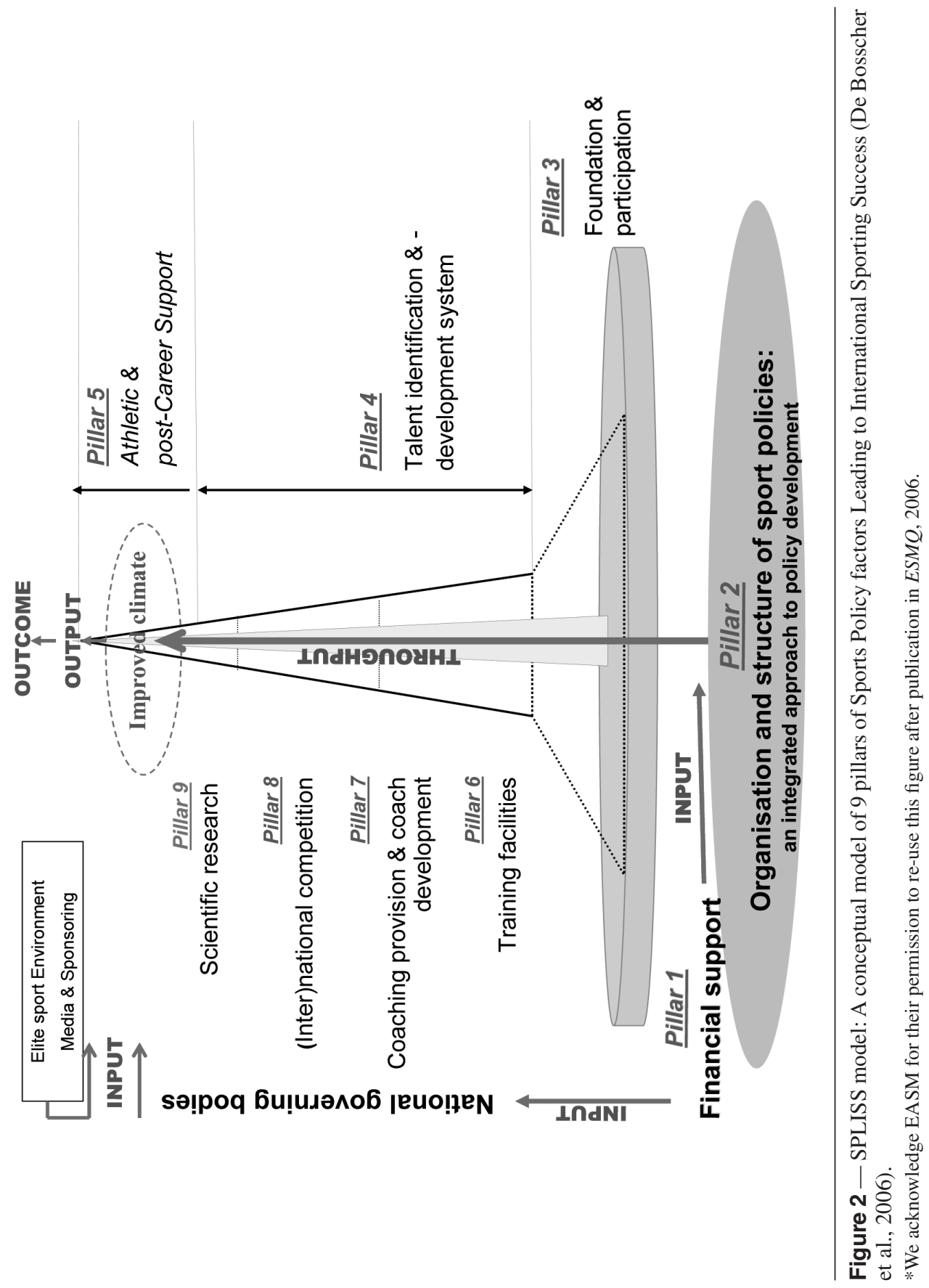


success factors can be operationalized in methodological terms, to measure competiveness. This was the intention of the second stage of the research, as explained below.

\begin{abstract}
Phase II: A Pilot Study to Develop a Method to Measure the Competitiveness of Nations in Elite Sport. Practitioners and academics have tried to qualify and quantify those characteristics that are present in highly competitive international businesses, where industries and firms are compared on a global scale to identify the most competitive (Sledge, 2005). Based on this approach, the second stage of this SPLISS study attempted to devise a method, to measure the sport policy determinants of competitiveness quantitatively, based on the conceptual framework and its CSFs as described above. A diagram of the procedures used in phase two to operationalize the nine pillars in an empirical environment during a pilot study with the six sample nations is presented in Appendix B1. During this stage, triangulation of methods was used, by which we mean a type of design in which different but complementary data are collected concurrently and analyzed against the conceptual model (Creswell \& Plano Clark, 2007). The researcher then attempts to merge the two data sets, typically by bringing the separate results together in the interpretation, and as in this study, to transform one data type (qualitative) into another data type (quantitative). The next section explains the sample selection for the pilot study and the organization of the research. This is followed by a discussion of the different steps in the research procedures.
\end{abstract}

\title{
Sample Selection
}

The six countries involved in the pilot study were: Belgium (separated into Flanders and Wallonia ${ }^{1}$ ), Canada, Italy, the Netherlands, Norway, and the United Kingdom. The selection of these nations was initially based on (1) the sport performances (to include good, medium and poorly achieving nations with the aim of observing differences in policies), (2) the countries' socioeconomic nature (western industrialised countries) and (3) a broadly comparable cultural background (general social development and population, sociology, ethnography). We tried to provide an even distribution of typical welfare states, as differentiated by Esping-Andersen (1990) in his research. In the end, the selection was merely pragmatic, due to limited research funds, and the need for reliable and engaged researchers in each nation who were sufficiently familiar with the elite sport structures in their own country and who were able to obtain funding to undertake the research. It should thus be noted that this research was a pilot study of six nations designed to explore a method and to operationalize a conceptual model empirically, rather than to evaluate the policies themselves.

\section{Organization of the Research}

Allowing for the complexity of international comparative research, the SPLISS study was coordinated by an international consortium group of seven researchers from three countries (Belgium (Flanders), the Netherlands and the United Kingdom). As the members were all internationally recognized researchers in elite sport, and in close contact with elite sport policy agencies in their nations, they acted as a group of experts throughout this research. Their role was: 
- to validate and refine the conceptual model (especially to improve content and construct validity);

- to define the CSFs and translate them into measurement questions;

- to supervise the objectivity of the data analysis, the internal validity, and the reliability; and especially,

- to ensure the international comparability of data.

Because of this extensive process, the research took four years. On average, two consortium meetings a year were organized and detailed information and discussions were exchanged via e-mail and telephone calls. The methodological approach of involving experts is proposed in several works on qualitative research methodologies (see for example, De Pelsmacker \& Van Kenhove, 1999; Gliner \& Morgan, 2000; Gratton \& Jones, 2004). As stated by Dellinger and Leech (2007), "construct validation is the continuous process of negotiation of meaning, which is accomplished through argument as dialogue, criticism and objection" (p. 320). This quotation accurately reflects the role of the consortium group in this research. The researchers from the four other countries (Canada, Norway, Italy, and Belgium (Wallonia) were involved, albeit to a lesser extent, in the process of assessing the researchers' reliability and the construct validity of the research instruments.

\section{Data Collection: Instruments}

The Critical Success Factors (CSFs) derived from the conceptual model described in the previous section were transformed into measurement questions. For the purpose of triangulation, as indicated in appendix B1, qualitative and qualitative data were used as a preparatory stage for quantification or measurement (De Pelsmacker \& Van Kenhove, 1999). These methods were combined because some CSFs are difficult to measure and they delivered complementary information on each pillar. A total of 103 CSFs were operationalized in the pilot study. ${ }^{2}$

Two research instruments were independently developed to collect data (De Bosscher et al., 2008): (1) the overall sport policy questionnaire completed by the researchers in each country and (2) the elite sport climate survey questionnaire completed by athletes, coaches, and performance directors. Overall, one third of the CSFs were developed through the elite sport climate survey and two-thirds through the overall sport policy questionnaire, similar to the World Competitiveness Yearbook (Rosselet, 2008). These research instruments were extensively discussed within the consortium group beforehand to avoid translation and interpretative difficulties and also to increase the validity of direct comparisons.

For the overall sport policy questionnaire, the researchers taking part in the SPLISS study in each country completed an extensive semistructured questionnaire on objective indicators or "facts," with 84 open-ended and closed questions in the nine pillars, including their evolution over the past ten years. These questionnaires were pretested in the three consortium nations and were adapted where necessary. The standardization of the CSFs to ensure that they are internationally comparable was particularly time consuming. Because of the detailed information required to answer all of the $103 \mathrm{CSF}$, the answers to these questions exceeded $30 \mathrm{~A} 4$ pages per country. The open-ended questions primarily sought to gain insight into each country's policy system for each pillar. Closed questions were added to ensure a 
degree of comparability for the various subcriteria. In addition to enable subsequent quantification, questions were subdivided in several dichotomous subquestions. For each question, space was left for additional comments and every pillar ended with two specific questions concerning: 1) the main strengths and weaknesses of the findings from each pillar; and 2) the researchers' suggestions for improving the elite sport policies in their country. These open sections also gave the researchers an opportunity to provide further details about possible additional criteria, that had not been included in the original questionnaires, but which were issues specific to their country. The degree of detail required to complete the policy questionnaire by the researchers was such that, for each nation, the task was a large-scale research project in its own right, for which researchers had to search for existing national surveys, analyze secondary sources and policy documents. Furthermore, depending on the data available and on the knowledge of the researcher, interviews with members of the National Olympic Committee and national sport governing bodies (NGBs) were conducted to provide answers to all of the CSFs.

The researchers received detailed written guidelines to help with the completion of the overall questionnaire and the methods were discussed in advance during a review meeting, to clarify possible ambiguities. A flowchart was presented with further instructions for completion regarding interviews and the search of secondary data sources. Researchers were required to provide comprehensive detail in their answers, and when a question did not seem clear, to ask for extra guidance. Furthermore, the researchers received two examples of completed questionnaires to ensure that the questions were interpreted correctly. To ensure the standardization of responses across the sample, and due to the international differences in sport systems, many questions were clarified later through meetings and other contact with the contributing researchers.

The second instrument was the elite sport climate survey. The term elite sport climate is defined by Van Bottenburg (2000) as "the social and organisational environment that provides the circumstances in which athletes can develop into elite sports athletes and can continue to achieve at the highest levels in their branch of sport" (p. 24). All participating countries were asked to undertake surveys of athletes, coaches, and performance directors, using self completion questionnaires before the 2004 Athens Olympic Games.

Given that some features of successful nations as defined by Oakley and Green (2001) and Clumpner (1994) cannot easily be quantified (throughputs), they can be assessed by their primary users, in this case the athletes and their coaches. In this respect, the survey served two purposes: (1) to gather information on objective indicators or "facts" that cannot easily be measured (using dichotomous questions, De Pelsmacker \& Van Kenhove, 1999) and (2) to assess the quality of elite sport development as it is perceived by the primary users, in this case the athletes and their coaches. This survey thus contained both "ojective data" (or facts) and perceived data. Our method, which is derived from the marketing and services literature, assumes that it is the consumers who best know the quality of a service as they experience it (Chelladurai \& Chang, 2000). It is also widely accepted in effectiveness literature that the primary stakeholders in sport organizations should be involved (Chelladurai, 2001; Papadimitriou \& Taylor, 2000; Shilbury \& Moore, 2006). The World Competitiveness Yearbook (Garelli, 2008; Rosselet, 2008) uses similar methods: a survey is conducted annually to complement objective data to 
quantify issues that are not easily measured and to measure competitiveness as it is perceived. Previous research in the area of national competitiveness has often been solely survey-based (Papanastassou \& Pearce, 1999). Criticisms of this method include concerns with small sample sizes, subjectivity and self-reporting bias. In an attempt to avoid these issues, our elite sport climate survey isolated objective data (facts) from perceived data (assessment). In this respect, our method differs from the World Competitiveness Yearbook and World Economic Forum studies.

One important issue in our survey was the comparability of the target groups. An elite athlete was defined according to the definition used by NOC*NSF (an amalgamation of the Netherlands Olympic Committee and the Netherlands Sport Federation) in the Netherlands as: "an athlete who, as an individual or as part of a team, has participated in an elite sport discipline in a European Championship (or a comparable event in other continents, e.g., Canada), World Championship, Olympic Games or other competitions that are comparable to these championships or games in the last twelve months."(II2) An elite coach was defined as "a coach who trains elite athletes or talented youths" and a performance director was defined as "the person who, within the national sport organisation [national governing body of sport] is responsible for elite sport." (I2) Finally, an elite sport discipline was defined as a discipline that meets the International Olympic Committee criteria or a minimum number of participating countries in World championships.

Finally the questionnaires were pretested in the Netherlands and Flanders and, after adaptations, the athletes' and performance directors' questionnaires both contained 71 questions and there were 76 questions included in the coaches' questionnaire. A research protocol was drafted for the researchers from the sample countries to increase the reliability of the research instruments, to standardize the procedures and to facilitate cross national comparisons on selected variables common to all surveys. This protocol contained a description of the proposed methods, definitions of the target groups and guidelines for the sports to be included in the research. Each nation also received three documents for each target group: a 'Word' template that could be used for the initial processing of the policy survey data in each country; a preformatted data file configured for analysis using the Statistical Package for the Social Sciences (SPSS) into which data from returned surveys could be entered; and an instruction manual to accompany the SPSS database, so as to avoid possible interpretative errors in the data input and analysis. Furthermore, it was emphasized that the questionnaires should remain unchanged, wherever possible, to ensure consistency of data collection and comparison across the samples. Questions could be added to the survey by individual nations, but they could not be deleted.

\section{Participants}

Although we wanted to open a debate on methods for international comparisons of elite sport policies rather than focusing on comparing policies themselves, we considered that the return of the questionnaires was informative because it demonstrated that the use of mixed research methods and the collection of data through both the overall sport questionnaire and a survey at an international level was both challenging and labor intensive.

Key informants from all six nations returned the overall sport questionnaire and provided additional information as required in several subsequent rounds of information gathering and clarification. 
Table 1 Overview of Response Rates From Athletes, Coaches, and Performance Directors in the Six Sample Nations

\begin{tabular}{lcccccc}
\hline & \multicolumn{2}{c}{ Athletes } & \multicolumn{2}{c}{ Coaches } & \multicolumn{2}{c}{$\begin{array}{c}\text { Performance } \\
\text { directors }\end{array}$} \\
\hline & Response & $\%$ & Response & $\%$ & Response & $\%$ \\
\hline The Netherlands & 421 & $34 \%$ & 62 & $28 \%$ & 28 & $52 \%$ \\
UK & 279 & $47 \%$ & 23 & $8 \%$ & $\mathrm{x}$ & $\mathrm{x}$ \\
Flanders & 140 & $43 \%$ & 119 & $51 \%$ & 26 & $100 \%$ \\
Canada & 132 & $16 \%$ & $\mathrm{x}$ & $\mathrm{x}$ & 11 & $32 \%$ \\
Wallonia & 63 & $41 \%$ & 16 & $20 \%$ & 06 & $19 \%$ \\
Norway & 55 & $58 \%$ & $\mathrm{x}$ & $\mathrm{x}$ & $\mathrm{x}$ & $\mathrm{x}$ \\
Italy & $\mathrm{x}$ & $\mathrm{x}$ & 32 & $64 \%$ & $\mathrm{x}$ & $\mathrm{x}$ \\
\hline TOTAL & 1090 & $34 \%$ & 253 & $29 \%$ & 71 & $45 \%$ \\
\hline
\end{tabular}

For the second instrument, the elite sport climate survey, the targeted response rate from athletes, coaches, and performance directors was $30 \%$ which is a reasonable return for postal surveys (De Pelsmacker \& Van Kenhove, 1999). Table 1 provides an overview of the responses by nation, respondent type, and response rates.

As can be seen in Table 1, the elite sport climate surveys from the six nations (seven regions) working together on this research differ significantly in terms of sample sizes. This is indicative of the opportunistic nature of the research and the limited funds secured by some nations to administer the elite sport climate survey (De Bosscher et al., 2008). Furthermore, as the research was highly dependent on the cooperation of sport authorities and National Olympic Committees, which had not necessarily commissioned the research, practical difficulties arose in accessing all three target groups (athletes, coaches, performance directors). These limitations should be taken into account and a pragmatic approach to the interpretation of the results is therefore needed. The data from several nations involved only a relatively small number of respondents ${ }^{3}$.In the athletes' survey, the targeted return of $30 \%$ was reached in all nations apart from Canada, where 132 athletes $(16 \%)$ returned usable questionnaires. Although the consortium group deliberated about excluding Canada from the survey for this reason, it was decided not to do so because there was still a large dataset on Canada from the overall sport policy questionnaire (which contained two-thirds of all the CSFs). Moreover, this study was a pilot study, which aimed to establish a method to measure the competitive position of nations, rather than to evaluate them.

Overall 253 responses were received from coaches. In Italy, the majority of coaches $(64 \%)$ were surveyed, while in the UK only $8 \%$ of coaches were reached. Given the low response rates from coaches in the UK (8\%) and in Wallonia (20\%), these results have not been used for further evaluation in this study.

A total of 71 performance directors from four different countries were surveyed and the sample size varied from $6(19 \%)$ in Wallonia to $28(52 \%)$ from the Netherlands and $26(100 \%)$ from Flanders. Given the low number of responses, these results were not used as success indicators throughout the study. However, they were highly informative in their own right to the countries in which they were completed. 
Despite the limitations of the sample, and bearing in mind that all six sample nations also conducted lengthy overall sport policy questionnaires (on which the majority (two-thirds) of CSFs are based), the research should be regarded as a useful step toward understanding the issues involved in making cross-national comparisons of elite sport systems. The unique feature of the research is that in addition to measuring easily quantifiable variables, such as inputs (e.g., money) and outputs (e.g., medals), it has also delved into understanding the "black box" of throughput both in terms of the existence of various system components and the rating that athletes, coaches, and performance directors provided to these system components. For example, while "effective communication" is a critical success factor for Pillar 2, this is not easy to evaluate and quantify, but it can be assessed by its primary users, in this case, the athletes and coaches.

\section{Data Analysis: An Illustration of the Scoring System Method}

The data analysis method is of primary concern in this paper, because it attempts to give insights into how elite sport policies have been measured, assessed, and aggregated into a scoring system. This approach was taken to allow other researchers to replicate the method and hopefully improve contemporary thinking in sport-related international comparative research.

This pilot study was an explorative way to initiate the development of a scoring system concerned with competitiveness in elite sport and a chance to gain an insight into the definition of qualitative standards for subsequent transformation into a quantitative score. The scoring system aims to express the general assessment of each pillar for each nation by consolidating different criteria into one final percentage score, which is suggested by De Pelsmacker and Van Kenhove (1999) as a typical method for measuring competitiveness in market research. Transformation of qualitative data into numeric counts in the literature involves reducing themes or codes to numeric information by simply counting the frequency with which specific codes occur. More research is required to expand the techniques for quantifying qualitative data and to develop the analysis options for data transformed this way (Creswell \& Plano Clark, 2007). The main difficulty in transforming data to create a measurement system concerns construct validity because of the absence of clear standards to rate an elite sport system objectively. The basis of the method in this respect is (1) data have partly been collected through a survey, which allowed us to quantify qualitative items and (2) the involvement of the consortium group as a team of experts in assessing each critical success factor.

The different steps used to create a scoring system are illustrated by exploring Pillar 2 (sport policies and structures) in depth. This pillar was chosen as an exemplar because it includes all types of questions and sources. A general overview of the success indicators and the scores for the six sample nations for this pillar is provided in Figure 3. The figure shows how ten evaluation criteria (of which three derive from the elite sport climate survey) and four perceived criteria were aggregated into one percentage score. A similar approach was taken for the other eight pillars. As discussed earlier, the evaluation of objective indicators and subjective indicators of each pillar were deliberately kept separate to calculate the score, which 
differs from the approaches of the World Economic Forum (2007) and the World Competitiveness Yearbook (Garelli, 2008; Rosselet, 2008). This was a deliberate decision to increase the interpretive reliability for evaluating an elite sport system.

A five-point scoring scale was used to assess each nation's performance against each CSF, with "one" indicating little development and "five" for a high level of development. There is no general consensus on the use of scales. For example the World Competitiveness Yearbook converts data from a 1-6 scale to a 0-10 scale and then calculates standard deviation values to determine rankings (Rosselet, 2008). The World Economic Forum converts the data to a scale of 1-7 (Önsel et al., 2008) and Sledge (2005) used a Likert scale of -1 to +2 to assess firms' strategies. The rationale for a 1-5 scale in this research was arbitrary but nonetheless consistent with the answers obtained on the overall sport questionnaire and the 1-5 ordinal scale used in the elite sport climate survey. Contrary to the economic competitiveness studies, relative rankings and the use of standardized measures based on averages or quartiles are inappropriate due to the small sample size of six nations.

Depending on the source (elite sport climate survey or overall sport policy questionnaire) and type of question (open-ended, dichotomous, or assessment), the standards for this five point scale differed. Generally there were three types of ratings.

1. The most complex ratings were derived from the overall policy questionnaire, because qualitative information on the elite sport systems for each pillar had to be transformed into a score for a five point scale. These (mostly) open-ended questions were grouped into categories to define the standards. Generally, the existence of specific aspects of the elite sport system were assessed in terms of 'availability of the criterion in a stronger or weaker form,' to indicate the level of development. An example of the attribution of these scores for open-ended questions from the overall sport policy questionnaire is given in Table 2 .

For each CSF, the standards and ratings were discussed within the consortium group until consensus was reached and, if necessary, further clarification of answers was sought from the researchers concerned.

2. In the elite sport climate survey quantitative data were available based on two types of questions: dichotomous questions (yes/no) and ratings on a five point Likert scale (ordinal). For the dichotomous questions absolute standards were used. When the CSFs contained several subindicators, as indicated in the example shown in Table 4, the scores were aggregated taking into account the non available answers. For the Likert scale questions 'net ratings' (i.e., positive answers minus negative answers) were calculated. An example of how the system was used in practice is shown in Tables 3, 4, and 5 .

Finally, an overall percentage score for each pillar was calculated by consolidating all the CSFs and by taking into account the number of "not available" (n/a) answers, given that not all countries achieved a score on the same number of criteria. When two thirds of the answers were not available for any nation, a score for that pillar was not calculated. When only two nations responded to a criterion, the criterion was deleted. A final percentage score was then calculated which ranged from $20 \%$ to $100 \%$. Scores lower than $20 \%$ are not possible as each nation received at least 1 point for each CSF. This was a deliberate choice because seldom is there "no development" at any level of sport policies. This $80 \%$ range was divided over a five point scale, with a range of 16 percentage points between each category. Using these scales, each nation was allocated a color-coded score or 'traffic light' 


\section{A. General score of Pillar 2 on facts or hard data}

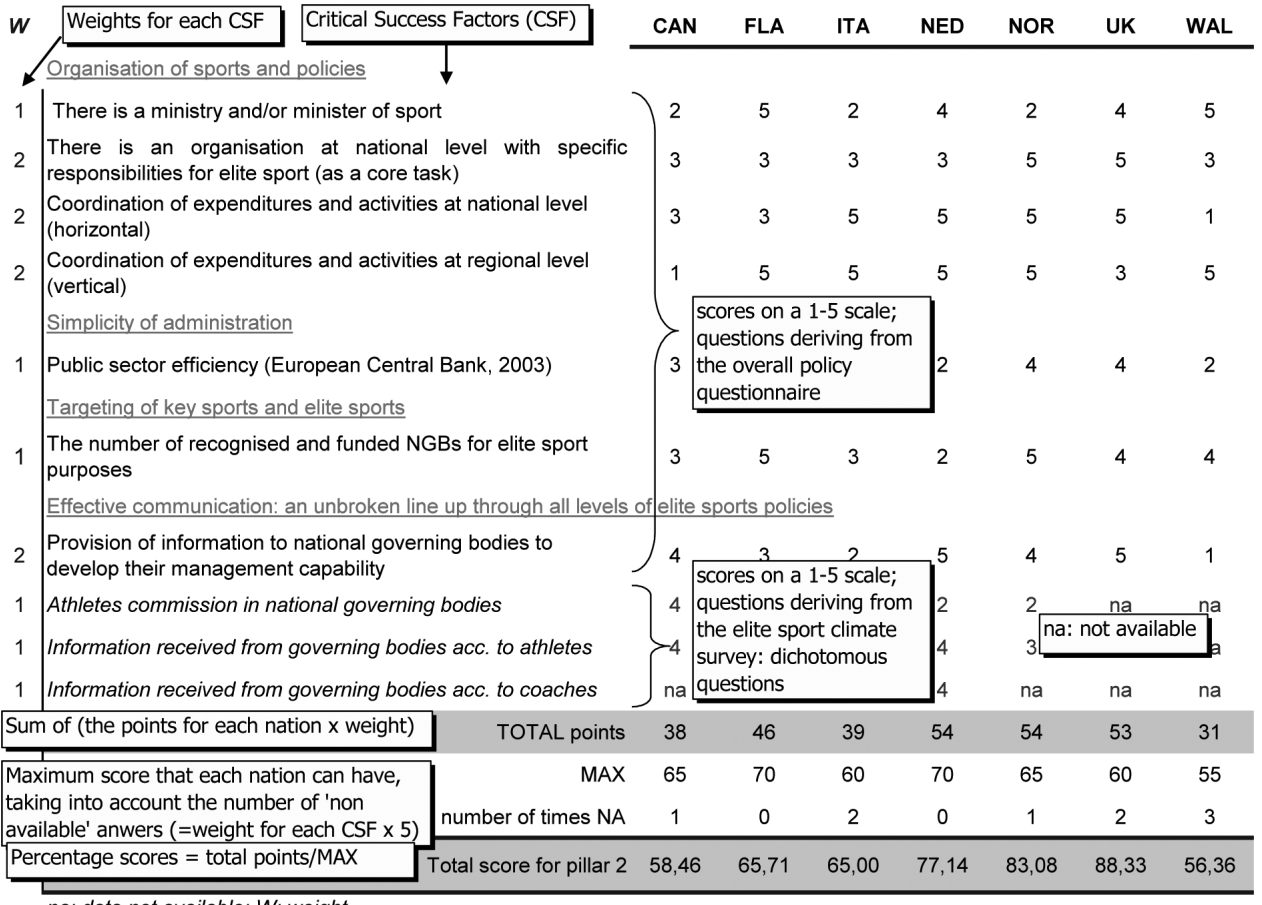

na: data not available; W: weight

Italic text: results from elite sports climate survey; non-italic text: results deriving from the overall sport policy questionnaire

\section{B. General score of Pillar 2 on perceived data or assessment}

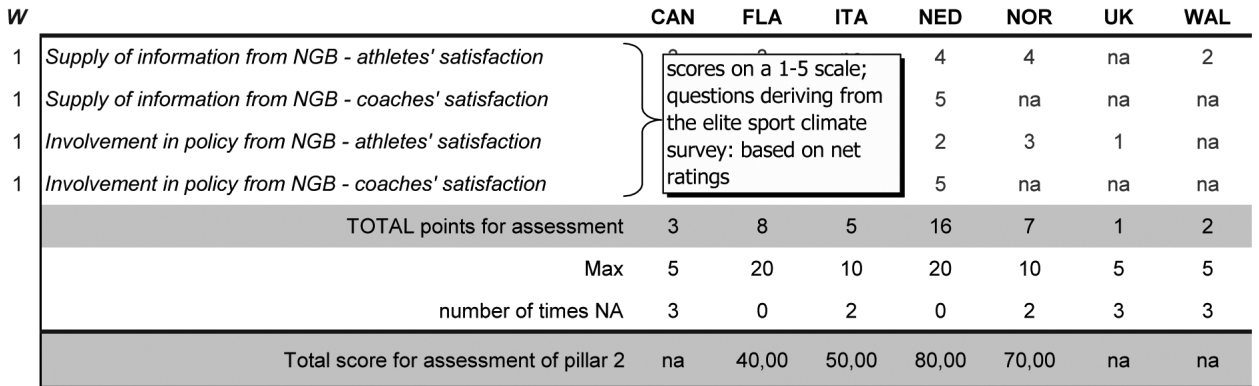

na: data not available; $W$ : weight

Italic text: results from elite sports climate survey; non-italic text: results deriving from the overall sport policy questionnaire

\begin{tabular}{llll}
\multicolumn{1}{c}{ Legend } & & & \\
CAN & Canada & NOR & Norway \\
FLA & Flanders & UK & United Kingdom \\
ITA & Italy & WAL & Wallony \\
NED & the Netherlands & &
\end{tabular}

Figure 3 - An illustration of Pillar 2 regarding the method used for development of a scoring system (De Bosscher et al., 2008). 
Table 2 An Illustration of the Points Attributed to an Open-Ended (Qualitative) Question From the Overall Sport Policy Questionnaire

CSF: Government/national sport bodies offer a post career support program to prepare and assist athletes for life after sport

\section{Score}

There is a good level of support for NGBs, including staff support (with personnel appointed for this), information dissemination and regular training opportunities

There is reasonable support through information provided to NGBs, regular training courses and policy planning but there are no staff appointed to assist NGBs

Support services and management information to NGBs are very limited

Support services and management information to NGBs are very limited
5 The Netherlands: 7 top sport account managers are appointed in NOC*NSF to assist NGBs, Bondnet (internet environment), marketing platform (information exchange) to assist NGBs on all different aspects of talent identification, development and professionalization

UKSport: modernization program;

4 Norway: in Olympiatoppen, a person is employed as an advisor for NGBs

Sport Canada has a number of consultants who work with NGBs to provide some guidance; furthermore, there are regularly training courses for NGBs; still, the guidance regarding professionalization of the management can be improved

3 Flanders: an evaluation with performance directors in 2003 showed that $60 \%$ of the NGBs claimed that they did not receive enough assistance on professionalization; remark that this has changed in 2004 with the establish ment of the department of elite sport (Bloso), however staffing support for NGBs is still limited.

2 Italy: no services related to organizational and professional aspects; regional schools of Sports of CONI organize courses for coaches and managers

1 Wallonia: no real assistance for NGBs on professionalization, quality, and talent identification

(black and white in this article), varying from a policy area 'very well developed' to 'little or no development' as shown in Figure 4. This approach was primarily to simplify the presentation of results and to identify any specific characteristics and trends in the overall results for the nine pillars.

Criteria were weighted to reflect the consortium's view of their relative importance. These weightings were needed primarily because each CSF was not measured by the same number of questions, and to "lock in" the impact of each 
Table 3 Illustration of the Points Attributed to Two Types of Questions in the Elite Sport Climate Survey: Dichotomous Questions and Ratings

\begin{tabular}{cccc}
\hline \multicolumn{2}{c}{ Dichotomous questions (yes/no) } & \multicolumn{2}{c}{ Ratings } \\
\hline$\%$ yes & Points & \% (pos.-neg.) & evaluation \\
\hline $0-20 \%$ & $1(-)$ & $<-19.9 \%$ & $1(-)$ \\
$20.1-40 \%$ & $2(-)$ & $0-(-19.9) \%$ & $2(-)$ \\
$40.1-60 \%$ & $3(0)$ & $0.1-20.0 \%$ & $3(0)$ \\
$60.1-80 \%$ & $4(+)$ & $20.1-50.0 \%$ & $4(+)$ \\
$80.1-100 \%$ & $5(++)$ & $>50.0 \%$ & $5(++)$ \\
\hline
\end{tabular}

Table 4 An Illustration of a Dichotomous Question for Pillar 2: About Which Subjects Do You Receive Information From Your Governing Body? (According to Athletes and Taken From the Athletes' Elite Sport Climate Survey)

\begin{tabular}{|c|c|c|c|c|c|c|}
\hline & & $\begin{array}{c}\text { CAN } \\
(N=126)\end{array}$ & $\begin{array}{c}\text { FLA } \\
(N=131)\end{array}$ & $\begin{array}{c}\text { NED } \\
(N=421)\end{array}$ & $\begin{array}{c}\text { NOR } \\
(N=55)\end{array}$ & $\begin{array}{c}\text { UK } \\
(N=273)\end{array}$ \\
\hline \multirow[t]{2}{*}{ Selection criteria } & \%yes & $93,4 \%$ & $56,8 \%$ & $75,3 \%$ & $80,0 \%$ & $90,8 \%$ \\
\hline & score & 5 & 3 & 4 & 4 & 5 \\
\hline \multirow[t]{2}{*}{ Nutrition } & \%yes & $49,5 \%$ & $16,5 \%$ & $24,8 \%$ & $18,2 \%$ & na \\
\hline & score & 3 & 1 & 2 & 1 & na \\
\hline \multirow[t]{2}{*}{ Doping } & $\%$ yes & $60,2 \%$ & $48,2 \%$ & $62,9 \%$ & $74,5 \%$ & $94,0 \%$ \\
\hline & score & 3 & 3 & 4 & 4 & 5 \\
\hline \multirow{2}{*}{$\begin{array}{l}\text { Training and } \\
\text { competition plans }\end{array}$} & $\%$ yes & $57,8 \%$ & $47,5 \%$ & $63,5 \%$ & $63,6 \%$ & na \\
\hline & score & 3 & 3 & 4 & 4 & na \\
\hline \multirow{5}{*}{$\begin{array}{l}\text { Scientific } \\
\text { research }\end{array}$} & $\%$ yes & $90,2 \%$ & $28,1 \%$ & $69,9 \%$ & $41,8 \%$ & $92,1 \%$ \\
\hline & score & 5 & 2 & 4 & 3 & 5 \\
\hline & Sum & 19 & 12 & 18 & 16 & 15 \\
\hline & MAX & 25 & 25 & 25 & 25 & 15 \\
\hline & $\begin{array}{l}\text { Total } \\
(\%)\end{array}$ & $76 \%$ & $48 \%$ & $72 \%$ & $64 \%$ & $100 \%$ \\
\hline \multicolumn{2}{|c|}{$\begin{array}{l}\text { Total score on CSF: } \\
\text { Athletes receive information } \\
\text { on different aspects } \\
\text { from their governing } \\
\text { bodies/governments }\end{array}$} & 4 & 2 & 4 & 3 & 5 \\
\hline
\end{tabular}

CSF on the overall score. To enhance the internal validity of our scoring system (De Pelsmacker \& Van Kenhove, 1999), the consortium group held several meetings devoted to the verification of the standards used to categorize the nations into five classes and to agree the weightings for each CSF. Nonetheless these weightings 
Table 5 An Illustration of a Net Rating Question for Pillar 2: How Do You Assess the Supply of Information From Your Governing Body? (According to Athletes and Taken From the Athletes' Elite Sport Climate Survey)

\begin{tabular}{lcccccc}
\hline & $\begin{array}{c}\text { Net } \\
\text { rating }\end{array}$ & $\begin{array}{c}\text { CAN } \\
(N=\mathbf{1 2 6})\end{array}$ & $\begin{array}{c}\text { FLA } \\
(N=\mathbf{1 2 6})\end{array}$ & $\begin{array}{c}\text { NED } \\
(N=\mathbf{4 1 4})\end{array}$ & $\begin{array}{c}\text { NOR } \\
(N=\mathbf{5 4})\end{array}$ & $\begin{array}{c}\text { WAL } \\
N \mathbf{5 8})\end{array}$ \\
\hline (5) Ample & $\mathrm{A}$ & $6,3 \%$ & $9,5 \%$ & $18,4 \%$ & $25,9 \%$ & $5,2 \%$ \\
(4) Enough & $\mathrm{B}$ & $33,3 \%$ & $34,1 \%$ & $39,1 \%$ & $24,1 \%$ & $27,6 \%$ \\
(3) Neutral & & $38,9 \%$ & $30,2 \%$ & $27,5 \%$ & $38,9 \%$ & $25,9 \%$ \\
(2) Insufficient & $\mathrm{C}$ & $12,7 \%$ & $17,5 \%$ & $9,2 \%$ & $7,4 \%$ & $25,9 \%$ \\
(1) Very & $\mathrm{D}$ & $8,7 \%$ & $8,7 \%$ & $5,8 \%$ & $3,7 \%$ & $15,5 \%$ \\
insufficient & & & & & & \\
No opinion & & $100,0 \%$ & & & & \\
& $\mathrm{~A}+\mathrm{B}$ & $39,7 \%$ & $43,7 \%$ & $57,5 \%$ & $50,0 \%$ & $32,8 \%$ \\
& $\mathrm{C}+\mathrm{D}$ & $21,4 \%$ & $26,2 \%$ & $15,0 \%$ & $11,1 \%$ & $41,4 \%$ \\
& $\mathrm{AB}-\mathrm{CD}$ & $18,3 \%$ & $17,5 \%$ & $42,5 \%$ & $38,9 \%$ & $-8,6 \%$ \\
& score & 3 & 3 & 4 & 4 & 2 \\
\hline
\end{tabular}

\begin{tabular}{cc|c}
\hline Total score (\%) & \multicolumn{2}{c}{ evaluation } \\
\hline $84.1-100 \%$ & Policy area very well developed & \\
\hline $68.1-84.0 \%$ & Good level of development & \\
\hline $52.1-68.0 \%$ & Moderate level of development & \\
\hline $36.1-52.0 \%$ & Fairly low level of development & \\
\hline $20.0-36.0 \%$ & Little or no development & \\
\hline
\end{tabular}

Figure 4 - Overall percentage scores: aggregated percentage scores of several CSFs (De Bosscher et al., 2008).

remain a subjective interpretation of a relative value of certain CSFs and therefore need to be explored in greater depth in future research.

Finally, to increase interobserver reliability of the data, the researchers of the sample nations $(n=10)$ were asked to check the final list of standards in general and the position of their country in particular. Furthermore policy makers and national sport governing bodies in each nation were asked to review the categories of standards and the information provided for their nation. Researchers from each nation, except Wallonia, returned this form with comments and proposed adjustments. For this reason the scores from Wallonia were often listed as "n/a" (not available), because there were too many gaps in the answers. 


\section{Discussion of Results (Pillar 2)}

As a last step, Figure 4 presents the black and white traffic light for Pillar 2 to provide an example of what can be learnt from this overall score.

The major point of note in Figure 5 is that there is little variation in the scores achieved by the six sample nations against Pillar 2, which perhaps endorses the point made by several authors that nations' elite sport development systems are becoming increasingly homogeneous (e.g., Bergsgard et al., 2007; Green \& Houlihan, 2008; Oakley \& Green, 2001). The positive scores achieved by Norway, the Netherlands, and the United Kingdom can in part be explained by the finding that, in each of these nations, both the government and the national sport governing bodies appear to be fully committed to the support and development of sport at elite level, with a clear delineation of responsibilities in elite sport and a high degree of coordination of expenditures and activities. Furthermore in the UK and the Netherlands, there is a highly-developed support system for national sport governing bodies whereas Norway's strength is to target its funds for elite sport (which are low level in absolute terms) to a limited number of sports.

Since the intention of this article was to explore a method to measure competitiveness of elite sport policies, we cannot dwell on the detailed comparison of the CSFs for Pillar 2. The main point is that the overall scores and traffic lights may increase insights into the extent to which nations are developed in managing their elite sport success. Replicating this approach for each pillar could help nations to uncover their strengths and weaknesses in a competitive international environment and thereby provide a basis for improving their policies. However, it should be noted that the proposed measurement system should not be isolated from general descriptive information on elite sport policies. A measurement system alone is not sufficient to compare elite sport systems. It should be guided by information on the general context, and the past changes in the nine pillars (De Bosscher et al., 2008). In this respect, the use of triangulation methods for the second stage of this research is important because qualitative data remain complementary to the quantitative measurement system. It is clear that the broad range of qualitative

\begin{tabular}{lccccccc} 
& CAN & FLA & ITA & NED & NOR & UK & WALI \\
\hline $\begin{array}{l}\text { Evaluation } \\
\begin{array}{l}\text { Assessment by athletes and } \\
\text { coaches }\end{array}\end{array}$ & 0 & $\ddots$ & $\bigcirc$ & $\ddots$ & $\bigcirc$ & $\bigcirc$ & $\bigcirc$ \\
\hline
\end{tabular}

key

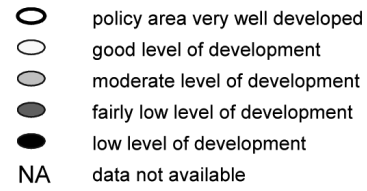

Figure 5 - Competitive analysis (traffic light, here in black and white) of six nations for Pillar 2: organization and structure of sport policies: an integrated approach to policy development (adapted from De Bosscher et al., 2008). 
information for the CSFs in the nine pillars was of major importance in enhancing our understanding of elite sport systems and explaining the scores derived.

\section{Discussion}

This paper aimed to explore a method used to measure the determinants of national elite sport success and its contribution to comparative sport research. Hence we endeavored to stimulate debate and open a dialogue on methods to compare elite sport policies of nations. Methods from economic studies were analyzed and partly translated to the context of elite sport on the assumption that competitiveness measurements in both fields are comparable, except for the outcomes: (mainly) economic profitability compared with international sporting success. Another distinction is the dependency of national governing bodies of sport on governmental support in most western welfare nations, which is not apparent to the same extent in economies. These two differences may explain why national policy in elite sport differs from national economic policies. It is therefore important in this study to bear in mind that quantitative findings alone are not sufficient to assess the quality of elite sport systems. The scoring system is in this regard a supportive and tangible way of understanding elite sport policies more broadly in relation to sporting success, rather than an isolated competitiveness measurement or ranking system on its own. Unlike laboratory experiments, studies on elite sport policies do not take part in a closed system. Qualitative description of elite sport policies and how they are formed remain essential units, even in a quantitative sport comparison.

The SPLISS study distinguishes itself from and is complementary to, both in methodological and theoretical terms, the work done by Bergsgard et al. (2007), Digel, Burk and Fahrner, M. (2006), Green and Houlihan (2005), and Houlihan and Green (2008) for two key reasons. First, the ultimate purpose of our work was to develop a theoretical model and to identify possible relationships between inputs, throughputs, and outputs in elite sport. Second, we used mixed research methods and a quantitative measurement system as techniques to compare our insights on how nations manage their future elite sport success. Mixed research methods were used for several purposes and at several levels: a sequential exploratory research and as part of this, a triangulation method. These methods were also suggested by Henry et al. (2005) to address in part the problems associated with cross-national research. The unique feature of this study is that in addition to measuring the easily quantifiable variables, it assesses processes by means of an elite sport climate survey (both objective and subjective data) with the main stakeholders in elite sport. In the overall score calculation, the survey data accounted for one third of the criteria. This method mirrored the economic World Competitiveness Yearbook, but nonetheless differed in two aspects: first, the deliberate choice to separate objective data from perceived data; and, second, the absence of relative rankings based on averages to calculate the scores. The latter is primarily related to the small sample of nations in this study, which in turn led to a more subjective scoring system. While objective scores can be calculated in the elite sport climate survey, the definition of standards in the overall sport questionnaire is somewhat arbitrary. It is based on comparative country data (where more is often better) and on the opinions of experts. The established collaboration with the consortium group helped to ensure that the data are more reliable and accurate and the method has been constantly fine-tuned. This 
method is typical in qualitative research, but nevertheless preserves some subjective elements. Further exploration of these methods in future research with more nations would allow statistical analysis, such as factorial and cluster analysis (construct validity) and correlations (criterion validity). However, this also raises questions about feasibility: is it realistic to conduct similar large-scale cross-national studies with other nations? Although the SPLISS consortium group aims to address this issue in future research, mixed research methods are time consuming (Cresswell \& Plano Clark, 2007) and this, in combination with the fact that the use of surveys in an international context is expensive, makes comparative studies very laborintensive and increases the need to deal carefully with the boundaries inherent in such cross-national comparisons. Nonetheless the findings reveal that these surveys are a useful way to evaluate a range of criteria that cannot easily be measured and for the complementary use of objective and perceived data. This latter point is also suggested in the effectiveness literature on national governing bodies of sport (Chelladurai \& Chang, 2000; Papadimitriou \& Taylor, 2000).

While this study addresses a meso-level comparison of competitiveness, it retains a focus that may need to be broadened to consider the debate about the natural resources of countries and their social, cultural, and historical background. This study has searched for a "fruitology of fruits," as suggested by Hofstede (1998), by detecting those elements that are comparable and can be fashioned by sport policies. However the capability of nations to survive and hold a competitive advantage in global markets also depends on elements such as: political and economic stability; natural resources; the efficiency of public institutions; the system of education; innovation strategies; health care provision; and so on. These were identified as macro-level factors in our theoretical model (De Bosscher et al., 2006). They were intentionally not included in the scoring system, but can be partly controlled for, by measuring the relative success of nations. To compare countries under ceteris paribus conditions, the residuals of a loglinear regression analysis can be used as a method to measure relative success, i.e., controlling for significant macro-variables (De Bosscher et al., 2007; De Bosscher, De Knop, \& Heyndels, 2003a, 2003b). However, some extraneous variables, including cultural characteristics and value systems, cannot be measured or quantified simply and this remains a core impediment to achieving construct validation of a theoretical model. Consequently, there is no single recipe for competitiveness, in either sport or in economies (Garelli, 2008; Porter, 1990).

The combination of the nine pillars may be specific to a given nation's local context and different elite sport systems may in fact all be successful. Consistent with the work of Esping Andersen (1990), individual nations will adapt policies to their own particular circumstances. Houlihan and Green (2008), referring to Kay (2005), highlighted an interesting notion in this respect, called path dependency, indicating that initial policy decisions can determine future policy choices-a process which may explain why the range of policy instruments used to develop an elite-focused policy may be applied differently.

A few comments should be made about the operationalization of the constructs. Despite attempts to develop a thorough conceptual model, albeit starting from a considerable deficiency in the literature, this model will need to be explored further in several directions to confirm the subscale structure. It is inherent with this type of research that a theoretical model will never be totally construct valid (Gliner \& 
Morgan, 2000). Similar to economic studies (Önsel et al., 2008; Porter, 1990), intercorrelation among the criteria is generally difficult to avoid. To give one example, the nine pillars are, in fact, related to each other and tend to be mutually reinforcing. For instance, each pillar in the throughput stage (P2-9) cannot be realized in a country lacking financial support (P1); a systematic talent recognition system (P4) will be reinforced by scientific research (P9); during the talent development stage (P4), athletes need to participate in international competitions (P8) and to make use of high quality facilities (P6). The significance here is the ongoing search for a reliable and valid set of criteria with the capacity to be applied to nations of a similar type and function. The third planned stage of deductive confirmatory research may contribute to this view but will not cover the whole complexity of theory development. A point of note in this respect is the dynamics of elite sport systems which are constantly evolving to establish success in the 'global sporting arms race' (De Bosscher et al., 2007). Practice often develops at a faster pace than theory.

\section{Notes}

1. Flanders is the northern, Dutch speaking part of Belgium, Wallonia the southern, French and German speaking part. In Belgium, the Flemish community (Flanders) and the French/German speaking community (Wallonia) have separate sport policies at each level, from local to national (including three separate ministers of sport). Apart from the Olympic Committee (BOIC), whose main task is to select athletes for the Olympic Games, there is no national (federal) policy or structure for sport, nor are there expenditures on sport at federal level. Therefore, Flanders and Wallonia have participated in this research as if they were two distinct nations. As the study includes to a large extent qualitative data, it is not possible to consider policies of Wallonia and Flanders into one final evaluation. Instead of excluding Belgium as a nation, it was decided with the consortium group to separate the two regions.

2. Some other CSFs were not included, because the study was limited to the overall national sport level (and they require sport-by-sport analysis) or because some CSFs required too much supplementary research within a nation. For example, this was the case with respect to data on expenditure on sport by local government or private investors, or data that are sport specific. Such data needed to be gathered at levels which fell beyond the scope of this research

3. In practice only Flanders, Wallonia, and the Netherlands surveyed all three target groups. The UK researchers did not interview performance directors; the Canadian researcher did not interview coaches; the Italian researchers did not interview athletes or performance directors; and the Norwegian researchers did not interview coaches or performance directors.

\section{Acknowledgments}

The authors would like to thank the dedicated researchers who joined this study: Jerry Bingham (UKSport), David Legg (Canada); Berit Skirstad and Torkild Veraas (Norway); Alberto Madella ${ }^{+}$and Lorenzo Di Bello (Italy); Bas Rijnen (the Netherlands); Chris Gratton (UK); Luc van de Puttee and Thierry Zintz (Wallonia); and Jerry Bingham (UKSport). The coordination of the research was funded by the Vrije Universiteit Brussel as part of doctoral-funding and by the other members of the consortium. Expenses for the research in the respective nations had to be covered by the researchers themselves. Financial constraints were the main barrier for more nations to be involved. We want to acknowledge the following organizations providing financial support: Olympiatoppen (Norway), CONI (Comitato Olimpico Nazionale Italiano, Italy), UKSport (UK), NOC*NSF (junction of 
the Netherlands Olympic Comittee and the Netherlands Sport Federation), Sport Canada (Canada), the ministers for sport from Flanders and Wallonia and the BOIC (Belgian Olympic Interfederal Comittee).

\section{References}

Augestad, P., \& Bergsgard, N.A. (2008). Norway. In B. Houlihan \& M. Green (Eds.), Comparative elite sport development (pp. 195-217). London: Elsevier.

Bergsgard, N.A., Houlihan, B., Mangset, P., Nødland, S.I., \& Rommetveldt, H. (2007). Sport policy. A comparative analysis of stability and change. London: Elsevier.

Broom, E.F. (1986). Funding the development of the Olympic athletes: A comparison of programs in selected Western and socialist countries. Proceedings of the third International Seminar on Comparative Physical Education and Sport (pp. 21-24). Champaign, IL: Human Kinetics.

Broom, E.F. (1991). Lifestyles of aspiring high performance athletes: A comparison of national models. Journal of Comparative Physical Education and Sport, 8(2), 24-54.

Bryson, L. (1992). Welfare and the state: Who benefits? London: Macmillan.

Buggel, E. (1986). The development of Sport in the German Democratic Republic: 19501985. Proceedings of the third International Seminar on Comparative Physical Education and Sport (pp. 37-53). Champaign, IL: Human Kinetics.

Castles, F.G., \& Mitchell, D. (1992). Three worlds of Welfare capitalism or four? Governance, 5(1), 1-26.

Chalip, L. (1995). Policy analysis in sport management. Journal of Sport Management, 9, 1-13.

Chalip, L., Johnson, A., \& Stachura, L. (Eds.). (1996). National sport policies: An international handbook. Westport, CT: Greenwood.

Chelladurai, P. (2001). Managing organizations, for sport \& physical activity. A system perspective. Scotsdale, AZ: Holcomb Hathaway.

Chelladurai, P., \& Chang, K. (2000). Targets and standards of quality in sport services. Sport Management Review, 3, 1-22.

Clumpner, R.A. (1994). $21^{\text {st }}$ century success in international competition. In R. Wilcox (Ed.), Sport in the global village (pp. 298-303). Morgantown, WV: Fitness Information Technology.

Conzelmann, A., \& Nagel, S. (2003). Professional careers of the German Olympic athletes. International Review for the Sociology of Sport, 38, 259-280.

Creswell, J.W., \& Plano Clark, V.L. (2007). Designing and conducing mixed methods research. London: Sage.

DaCosta, L., \& Miragaya, A. (2002). Worldwide experiences and trends in sport for all. Oxford, UK: Meyer \& Meyer Sport.

De Bosscher, V., Bingham, J., Shibli, S., van Bottenburg, M., \& De Knop, P. (2008). A Global sporting arms race. An international comparative study on sports policy factors Leading to international sporting success. Aachen, DE: Meyer \& Meyer.

De Bosscher, V., De Knop, P., \& Van Bottenburg, M. (2007). Sports Policy Factors Leading to International Sporting Success. Published doctoral thesis. Brussels, BE: VUBPRESS.

De Bosscher, V., De Knop, P., van Bottenburg, M., \& Shibli, S. (2006). A conceptual framework for analysing Sports Policy Factors Leading to international sporting success. European Sport Management Quarterly, 6, 185-215.

De Bosscher, V., De Knop, P., van Bottenburg, M., Shibli, S., \& Bingham, J. (2009). Explaining international sporting success. An International comparison of elite sport systems and policies in six nations. Sport Management Review, 12, 113-136.

De Bosscher, V., De Knop, P., \& Heyndels, B. (2003a). Comparing relative sporting success among countries: Create equal opportunities in sport. Journal of Comparative Physical Education and Sport, 3(3), 109-120. 
De Bosscher, V., De Knop, P., \& Heyndels, B. (2003b). Comparing tennis success among countries. International Sport Studies, 1, 49-69.

De Knop, P., Engström, L.M., Skirstad, B., \& Weiss, M.R. (1996). Worldwide trends in youth sport. Champaign, IL: Human Kinetics.

Dellinger, A.B., \& Leech, N.L. (2007). Toward a unified validation framework in mixed methods research. Journal of Mixed Methods Research, 1(4), 309-332.

Depperu, D., \& Cerrato, D. (2008). Analysing international competitiveness at the firm level: concepts and measures. Retrieved August 15, 2008 from http://www3.unicatt. it/unicattolica/dipartimenti/DISES/allegati/wpdepperucerrato32.pdf

De Pelsmacker, P., \& Van Kenhove, P. (1999). Marktonderzoek: methoden en toepassingen [Market research: methods and applications] ( $3^{\text {rd }}$ ed.). Leuven - Apeldoorn, BE: Garant.

Digel, H., \& Barra, M. (2004). Hochleistungssport in Italien [high level sport in Italy]. Weilheim/Teck, Tubingen, DE: Bräuer.

Digel, H., Burk, V., \& Fahrner, M. (2006). High-performnce sport. An international comparison. Edition Sports International, 9. Weilheim/Teck. Tubingen, DE: Bräuer.

Digel, H., Burk, V., \& Sloboda, H. (2006). Hochleistungssport in Russland [high level sport in Russia]. Weilheim/Teck, Tubingen, DE: Bräuer.

Digel, H., \& Fahrner, M. (2003). Hochleistungssport in Frankreich [high level sport in France]. Weilheim/Teck, Tubingen, DE: Bräuer.

Digel, H., Fahrner, M., \& Utz, A. (2005). Hochleistungssport in den USA [high level sport in the USA]. Weilheim/Teck, Tubingen, DE: Bräuer.

Digel, H., \& Kruse, A. (2004). Hochleistungssport in Australien [high level sport in Australia]. Weilheim/Teck, Tubingen, DE: Bräuer.

Digel, H., Burk, V., \& Sloboda, H. (2003). Hochleistungssport in Großbritannien und Nordirland [high level sport in Great Britain and Northern Ireland]. Weilheim/Teck, Tubingen, DE: Bräuer.

Digel, H., Miao, J., \& Utz, A. (2003): Hochleistungssport in China [high level sport in China]. Weilheim/Teck, Tubingen, DE: Bräuer.

Douyin, X. (1988). A comparative study on the competitive sports training systems in different countries. Journal of Comparative Physical Education and Sport, 2(3), 3-12.

Duffy, P., Lyons, D., Moran, A., Warrington, G., \& Macmanus, C. (2001). Factors promoting and inhibiting the success of high performance players and athletes in Ireland. Retrieved January 20, 2002, from http://www.nctc.ul.ie/press/pubs/Success\%20 Factors\%20STUDY.doc.

Esping-Andersen, G. (1990). The three worlds of welfare capitalism. Cambridge, UK: Polity Press.

Garelli, S. (2008). Competitiveness of nations: the fundamentals. International Institute for Management Development, World Competitiveness yearbook. Retrieved August $2^{\text {nd }}$, 2008: http://www02.imd.ch/wcc/yearbook

Gibbons, T., McConnel, A., Forster, T., Riewald, S.T., \& Peterson, K. (2003). Reflections on success: US Olympians describe the success factors and obstacles that most influenced their Olympic development. Report phase II, United States Olympic Committee. USOC.

Gliner, J.A., \& Morgan, G.A. (2000). Research methods in applied settings: an integrated approach to design and analysis. Mahwah, NJ: Lawrence Erlbaum Associates.

Gratton, C., \& Jones, I. (2004). Research methods for sport studies. London: Routledge.

Green, B.C. (2005). Building Sport programs to optimize athlete recruitment, retention and transition: toward a normative theory of sport development. Journal of Sport Management, 19, 233-253.

Green, M. (2005). Integrating Macro- and Meso-level Approaches: A comparative analysis of elite sport development in Australia, Canada and the United Kingdom. European Sport Management Quarterly, 2, 143-166.

Green, M., \& Collins, S. (2008). Policy, politics and path dependency: Sport development in Australia and Finland. Sport Management Review, 11, 225-251. 
Green, M., \& Houlihan, B. (2005). Elite sport development. Policy learning and political priorities. London: Routledge.

Green, M., \& Oakley, B. (2001). Elite sport development systems and playing to win: Uniformity and diversity in international approaches. Leisure Studies, 20, 247-267.

Greenleaf, C., Gould, D., \& Diefen, K. (2001). Factors influencing Olympic performance with Atlanta and Nagano US Olympians. Journal of Applied Sport Psychology, 13, 154-184.

Haag, H. (1994). Triangulation: A strategy for upgrading comparative research methodology in sport science. In R. Wilcox (Ed.), Sport in the global village (pp. 501-507). Morgantown, WV: Fitness Information Technology.

Hanafy, E.H., \& Krotee, M.L. (1986). A model for international education comparison: Middle East perspective. In T. Bedecki (Ed.) Proceedings of the third international seminar on comparative physical education and sport (pp. 253-266). Champaign, IL: Human Kinetics.

Henry, I. (2007). Bridging research traditions and world views: universalisation versus generalisation in the case for gender equity. In I. Henry and the Institute of Sport and Leisure Policy (Eds.). Transnational and comparative research in sport. Globalisation, governance and sport policy (pp. 197-212). London: Routledge.

Henry, I., Amara, M., \& Al-Tauqi, M. (2005). A typology of approaches to comparative analysis of sports policy. Journal of Sport Management, 19, 520-535.

Hofstede, G. (1998). A case for comparing apples with oranges: International differences in values. International Journal of Comparative Sociology, 39, 16-31.

Houlihan, B. (1997). Sport, policy and politics. A comparative analysis. London: Routledge.

Houlihan, B., \& Green, M. (2008). Comparative elite sport development. London: Butterworth-Heineman.

Kamphorst, T.J., \& Roberts, K. (1996). Trends in sports: A multinational persective. Culemborg, NL: Giordano Bruno.

Kay, A. (2005). A critique of the use of path dependency in policy studies. Public Administration, 83, 553-571.

Krüger, A. (1984). To Moscow and back: International status of comparative research in regard to physical activity outside of schools. Proceedings of the 4th International Seminar on Comparative Physical Education and Sport. Malente-Kiel, West Germany, 213-227.

Krüger, A. (1989). The sportification of the world: are there any differences left? Journal of Comparative Physical Education and Sport, 2(3), 5-16.

Linssen, G.W.J.M. (1998). Benchmarking. De concurrentietoets 1997: Een voorbeeld van benchmarken [An example of benchmarking]. Beleidsanalyse, 1, 14-22.

Nys, K. (2002). Prestatiebepalende factoren in topsport [Factors determining international success in elite sports]. Unpublished master's thesis, Vrije Universiteit Brussel, Belgium.

Oakley, B., \& Green, M. (2001). The production of Olympic champions: International perspectives on elite sport development system. European Journal for Sport Management, 8, 83-105.

Önsel, S., Ülengin, F., Ulusoy, G., Aktas, E., Kabak, Ö., \& Topcu, I. (2008). A new perspective on the competitiveness of nations. Socio-Economic Planning Sciences, 42, 221-246.

Panastassou, M., \& Pearce, R. (1999). Multinationals, technology and national competitiveness. Cheltenham, UK: Edward Elgar.

Papadimitriou, D., \& Taylor, P. (2000). Organisational effectiveness of Hellenic national sports organisations: A multiple constituency approach. Sport Management Review, 3, 23-46.

Pedhazur, J., \& Schmelkin, L.P. (1991). Measurement, Design, and Analysis. An integrated approach. Hillsdale, New Jersey: Lawrence Erlbaum Associates publishers.

Porter, M.E. (1990). The competitive advantage of nations. London: Macmillan Press.

Riordan, J. (1989). Soviet sport and Perestroika. Journal of Comparative Physical Education and Sport, 6, 7-18. 
Riordan, J. (1991). Sport, politics and communism. Manchester, UK: Manchester University Press.

Rosselet, S. (2008). Methodology and principles of analysis. International Institute for Management Development World Competitiveness yearbook. Retreived August 2, 2008 from http://www02.imd.ch/wcc/yearbook

Sainsbury, D. (1994). Gendering welfare states. London: Sage.

Sedlacek, J., Matousek, R., Holcek, R., \& Moravec, R. (1994). The influence of the political changes on the high performance sport organisation in Czechoslovakia. In R. Wilcox (Ed.), Sport in the global village (pp. 341-347). Morgantown, WV: Fitness Information Technology.

Semotiuk, D.M. (1990). East Bloc athletics in the Glasnost era. Journal of Comparative Physical Education and Sport, 9(1), 26-29.

Shibli, S., \& Bingham, J. (2008). A forecast for the performance of China in the Olympic Games 2008 and the unverlying performance management issues. Managing Leisure, $13,1-21$.

Shilbury, D., \& Moore, K.A. (2006). A study of organizational effectiveness for national Olympic sporting organizations. Nonprofit and Voluntary Sector Quarterly, 35, 5-38.

Sledge, S. (2005). Does Porter's diamond hold in the global automotive industry? Advances in Competitiveness Research articles, 13(1), 22-32.

Sotiriadou, K., Shilbury, S., \& Quick, S. (2008). The attraction, retention/transition and nurturing process of sport development: Some Australian evidence. Journal of Sport Management, 22, 247-272.

Stamm, H., \& Lamprecht, M. (2000). Der Schweizer Spitzensport im internationalen Vergleich. Eine empirische Analyse der Olympischen Spiele, 1964-1998. GSF-schriften sportwissenschaften. Zürich: Studendruckerei Uni Zürich. [An international comparison of Swiss high level sport: An empirical analysis of the Olympic Games, 1964-1998].

Tashakkori, A., \& Teddlie, C. (2003). Handbook of mixed methods in social and behavioural research. London: Sage.

Unierzyski, P. (2002). Why some good juniors succeeded and some others did not. Retrospective analysis of players born in 1981-1983. In Tennis Europe (Ed.) Proceedings of the European Coaches Symposiums (pp. 1-6). Vale do Lobo, PT: Tennis Europe.

Van Bottenburg, M. (2000). Het topsportklimaat in Nederland [The elite sports climate in The Netherlands]. 's Hertogenbosch, the Netherlands: Diopter-Janssens and van Bottenburg bv.

Van Bottenburg, M. (2002). Sport for all and elite sport: Do they benefit one another? In NOC*NSF (Ed.), Proceedings of the $9^{\text {th }}$ World Sport for All Congress. 'Sport for All and Elite Sport: Rivals or partners? (p. 25). Ahrnem, the Netherlands: NOC*NSF.

Van Bottenburg, M., Rijnen, B., \& Van Sterkenburg, J. (2005). Sports participation in the European Union. Trends and differences. 's Hertogenbosch, The Netherlands: W.J.H. Mulier Institute and Nieuwegein: Arko Sports Media.

World Economic Forum. (2007). The global competitiveness report 2007. World Economic Forum. New York: Palgrave Macmillan.

Wylleman, P., De Knop, P., \& Sillen, D. (1998). Former Olympic athletes' perceptions of retirement from high-level sport. Paper presented at the $28^{\text {th }}$ Congress of the International Association of Applied Psychology, San Francisco, CA. 


\section{Appendices}

\section{APPENDIX A1:}

A visual diagram of the procedures used in phase one to develop a conceptual model of SPLISS, based on Creswell \& Plano Clark (2007)

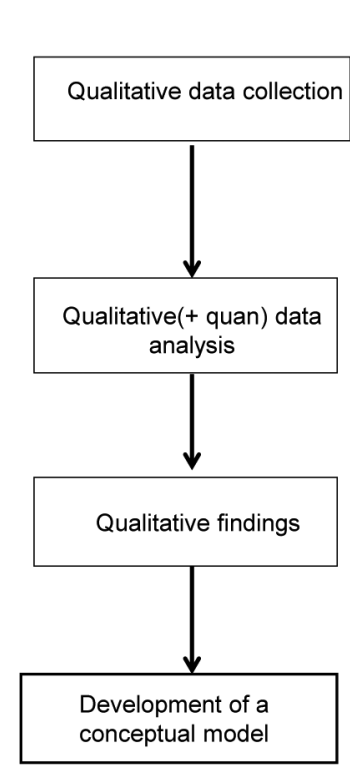

Procedures:

- literature review: macro-meso-micro

- (concurrently) two experimental preliminary studies, with open ended questions:

- questionnaires to athletes $(n=114)$, coaches $(n=99)$ and performance directors $(n=$ 26) in Flanders $\rightarrow$ consumer perspective

- questionnaires to international tennis experts (22 countries) $\rightarrow$ expert perspective

Products:

- literature notes and written responses

Procedures: repeated twice, by 2 independent researchers (construct validity)

- inductive content analysis (mesolevel): thematic development from quotations ( $a / b$ level: into broader categories (A/B level)

- count frequencies (in preliminary studies)

Products:

- classification of themes and dimensions, with indication of frequency (quan)

Procedures:

- description of themes and dimensions

Products:

- nine dimensions subdivided by different themes

$\rightarrow$ presented (independently) to consortium group ( $n=5$ experts) and discussed ( 2 days meeting) to regroup themes as regards increasing construct and content validity

Procedures:

- write themes as Critical Success Factors (CSFs)

- define outputs: what is success? (criterion validity)

Products:

- CSFs across nine pillars (dimensions), situated at the level of inputs and throughputs, that may increase probability of outputs

- different methods to measure success: absolute vs. relative success, summer and winter sports, medals or top eight (or sixteen) places, different events,...)

\section{APPENDIX B1:}

A visual diagram of the procedures used in phase two to operationalize nine pillars in an empirical environment during a pilot study with six nations and to explore a method to measure the competitive position of nations, based on Creswell \& Plano Clark (2007) 


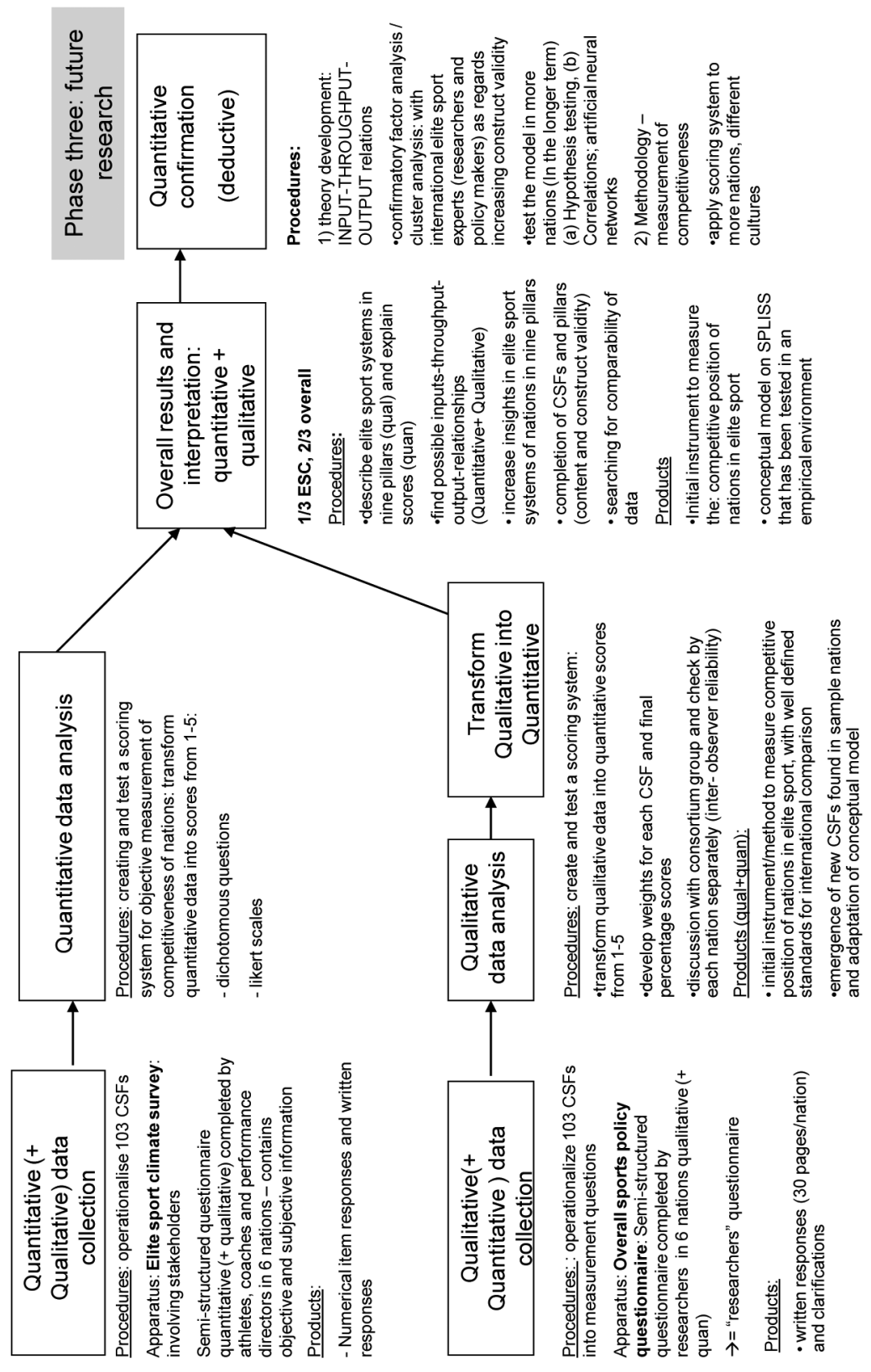




\section{APPENDIX C1: Research Steps and Evaluation of Validity and Reliability}

\section{Validity and reliability Research procedures}

\section{Stage 1: Development of a conceptual model (competitiveness determinants)}

Face validity

Content validity:

- nine pillars

- detailed CSFs

Criterion validity

Construct validity
Does the model measure what we want it to measure at first glance?

XXX Literature review

Are the nine pillars the right competitiveness

determinants?

- Literature review: macro-meso-micro (factors influencing international sporting success); economic studies (methodological)

- Preliminary research, survey with:

- Stakeholders (athletes, coaches, performance directors in Flanders)

- International experts (tennis)

- International consortium group (experts opinion's) Is success clearly defined?

Define criterion (outputs): different methods to measure success (absolute, relative, summer and winter sports, different events, medals or top eight places,... . ) Are the CSF related with success?

- Literature review: macro-meso-micro

- Preliminary research, survey with:

- Stakeholders (athletes, coaches, performance directors in Flanders)

- International experts (tennis)

- International consortium group (experts opinion's) Are the concepts measured correctly and with all it's facets?

- See above, for completion of the nine pillars and it's CSF

- clustering of items by two independent researchers

- International consortium group (experts opinion's) — two days meeting: to classify the CSF, to define CSF clearly, eventually add and delete CSF

Stage 2: Pilot study with six nations

\section{A. Transformation of pillars and CSF into questions and data collection procedures}

Validity (internal)

Has the theory been correctly transformed into practice? Are the questions sufficiently covering the nine pillars and it's CSF? (construct validity) Were the questions correctly defined; can't they be misinterpreted? (internal validity)

- Literature on transnational studies in different areas (methodology) 
Internal and external

reliability

(interpretive

consistency and

interrater reliability)
- Transformation of nine pillars and it's CSF into measurement questions:

- discussed with consortium group (meetings, emails and conference calls) to avoid translation and interpretative difficulties; increase the validity of direct comparisons

- Careful sample selection

Two surveys

1) Elite sport climate survey (opearationalization of $1 / 3$ of the CSF)

- aim: (1) collect data on questions that are difficult to measure and (2) stakeholders' perspective in elite sport - Before the Athens Olympic Games

- Measures objective (facts) and subjective (satisfaction) indicators; these are kept separated

- Pretested in two nations (Flanders and the Netherlands) and adapted where necessary

2) Overall sport policy questionnaire (opearationalization of $2 / 3$ of the CSF)

- aim: measure objective indicators or "facts" and get insights in international elite sport policies of nations

- Researchers' questionnaire: a comprehensive research by itself, collected through secondary sources and (eventually) interviews

- (for each pillar) questions: open-ended (to gain insight) and closed (comparability); strengths and weaknesses and past ten years evolutions

- Pretested in three consortium nations

- Clarifications through emails and telephones

- Careful selection of researchers in the sample nations (knowledgeable, precise, good relations with policy, find funds)

- Organization of initial meetings, to explain the methods 1) Procedures in the elite sport climate survey

- Research protocol and definitions (athlete, coach, coordinator, elite sports discipline);

- Questions can be added, but remain unchanged - Advise to conduct local interviews (reproduce data to own context)

2) Procedures in the overall sport policy questionnaire - guidelines and flowchart with information

- two examples of completed questionnaires as an example

- asked for sufficiently comprehensive detail and not fill in if unclear

- further clarification later through e-mail and telephone Analysis: elite sport climate survey

- word template, SPSS file and manual 


\section{Stage 2: Pilot study with six nations}

\section{B. data-analysis: development of a scoring system and the introduction of 'measurement'}

\section{Reliability}

Construct validity of the measurement instrument
Is the sample representative?

- There are only six sample nations, because the aim was to explore a measurement tool and to refine a conceptual model

Overall sports policy questionnaire:

- completed by each nation $(\mathrm{N}=7)$

Elite sport climate survey:

- Intervening variables on the sample are mentioned in the paper;

- It should therefore be noted that results may be biased by nonresponse

- The response rate is below $30 \%$ for Canadian athletes $(16 \%, \mathrm{~N}=116)$ and Dutch coaches $(28 \%)$

- Walloon coaches $(19 \%, \mathrm{~N}=6)$ and UK coaches $(8 \%, \mathrm{~N}=23)$ were excluded; data from performance directors were excluded

- Remark: the Netherlands did a nonresponse check for their athletes and coaches and found a high correlation $(\mathrm{r}>.8)$

Have scores and weights adequately been assigned?

- Standards to develop scores in the overall sport policy questionnaire are to some extent arbitrary (they are expressed in terms of 'availability' - the more, the better). Weights are added to "lock in" the impact of each CSF on the overall score;

- to increase validity of this procedure, all standards and weights were discussed with a group of experts (consortium group) during several longstanding meetings - the standards were finally checked by the researchers of each nation and their policy makers

- The elite sport climate (quantitative information) allowed to create objective standards for comparison and develop five point categories

Is the score adequate for the concept measured? Are all facets of the factors leading to success measured? - The profoundly defined set of CSF, and the use of two different instruments intend to increase construct validity of the measurement instrument - 2/3 of the CSF derive from the overall sports policy questionnaires, $1 / 3$ from the elite sport climate survey - increase construct validity hard data were separated from perceived data

- The definition of relative success allows inclusion of macro-level factors to some extent (wealth, population, political system, religion, geography) 
Criterion validity

boundaries:

- some data should be measured at other levels (sport specific, local policies and sponsorships)

- representativeness of the pilot study and the sample; n/a (not available) scores for some nations on certain $\mathrm{CSF}$

- small sample (6 nations) does not allow the use of relative values or averages for missing values

- not all pillars have an assessment

- many extraneous factors that can't be measured in quantitative terms (cultural, historical)

Are the results related to an external criterion or is there a relation between success (outputs) and the scores on nine pillars (inputs and throughputs)? Is each indicator related to success?

- The development of a scoring system is especially important to increase criterion validity

- The study cannot be conclusive on a possible inputoutput relationship because:

- it is not possible to make statistical relations with only six sample nations; no causalities

- definition of success is ambiguous: absolute, relative, winter sports, summer sports, . . . all giving different rankings for the nations

- there are many extraneous factors, that influence success

- further research is needed at other levels (e.g., sport by sport) 